\title{
Surface-Coated Polylactide Fiber Meshes as Tissue Engineering Matrices with Enhanced Cell Integration Properties
}

\author{
Matthias Schnabelrauch, ${ }^{1}$ Ralf Wyrwa, ${ }^{1}$ Henrike Rebl, ${ }^{2}$ \\ Claudia Bergemann, ${ }^{2}$ Birgit Finke, ${ }^{3}$ Michael Schlosser, ${ }^{4}$ Uwe Walschus, ${ }^{4}$ \\ Silke Lucke, ${ }^{4}$ Klaus-Dieter Weltmann, ${ }^{3}$ and J. Barbara Nebe ${ }^{2}$ \\ ${ }^{1}$ Biomaterials Department, INNOVENT e. V., Prüssingstraße 27B, 07745 Jena, Germany \\ ${ }^{2}$ Department of Cell Biology, University Medical Center Rostock, Schillingallee 69, 18057 Rostock, Germany \\ ${ }^{3}$ Leibniz-Institute for Plasma Science and Technology e. V. (INP), Felix-Hausdorff-Straße 2, 17489 Greifswald, Germany \\ ${ }^{4}$ Research Group of Predictive Diagnostics, Department of Medical Biochemistry and Molecular Biology, \\ Ernst-Moritz-Arndt University of Greifswald, Greifswalder Straße 11c, 17495 Karlsburg, Germany
}

Correspondence should be addressed to Matthias Schnabelrauch; ms@innovent-jena.de

Received 6 February 2014; Accepted 20 May 2014; Published 15 June 2014

Academic Editor: Nicholas Dunne

Copyright (c) 2014 Matthias Schnabelrauch et al. This is an open access article distributed under the Creative Commons Attribution License, which permits unrestricted use, distribution, and reproduction in any medium, provided the original work is properly cited.

Poly(L-lactide-co-D/L-lactide)-based fiber meshes resembling structural features of the native extracellular matrix have been prepared by electrospinning. Subsequent coating of the electrospun fibers with an ultrathin plasma-polymerized allylamine (PPAAm) layer after appropriate preactivation with continuous $\mathrm{O}_{2} / \mathrm{Ar}$ plasma changed the hydrophobic nature of the polylactide surface into a hydrophilic polymer network and provided positively charged amino groups on the fiber surface able to interact with negatively charged pericellular matrix components. In vitro cell experiments using different human cell types (epithelial origin: gingiva and uroepithelium; bone cells: osteoblasts) revealed that the PPAAm-activated surfaces promoted the occupancy of the meshes by cells accompanied by improved initial cell spreading. This nanolayer is stable in its cell adhesive characteristics also after $\gamma$-sterilization. An in vivo study in a rat intramuscular implantation model demonstrated that the local inflammatory tissue response did not differ between PPAAm-coated and untreated polylactide meshes.

\section{Introduction}

Electrospinning is a long-known polymer processing technique that has received remarkable interest during the last decade for biomedical applications like tissue engineering and drug delivery [1-5]. The technique is applicable to both polymer solutions and melts $[6,7]$ and enables the fabrication of made-on purpose tissue engineering matrices resembling major structural features of the native extracellular matrix $[8,9]$. Polymer meshes resulting from electrospinning are characterized by an interconnective porous network of more or less ordered polymeric fibers with diameters in the range between $3 \mathrm{~nm}$ and $2.5 \mu \mathrm{m}$. Those artificial matrices are of great interest in tissue reconstruction to act as cell support guiding cell adhesion, proliferation, and differentiation [10, 11]. Both natural polymers like collagen [12, 13], silk [14], or different polysaccharides [15] and synthetic polymers particularly the well-known biodegradable polylactones [16], polyanhydrides [17], or polyurethanes [18] are well suited for processing by this technique.

The principal applicability of electrospun fiber meshes made of artificial polymers like polylactones for cell cultivation purposes has been shown in numerous studies using different cell types including cardiomyocytes [19], smooth muscle cells [20], keratinocytes [21], fibroblasts [22], and osteoblasts [23].

With regard to their use as tissue engineering scaffolds, a drawback of many synthetic polymers is their innate hydrophobicity which often impairs initial protein adsorption and cell adhesion [24]. Different strategies have been proposed to overcome this problem including the synthesis 
of block copolymers containing hydrophilic segments [25], the coating of synthetic polymer surfaces by natural polymers like collagen [26], or the attachment of cell adhesion molecules onto the polymer surface [27]. A promising and recently established strategy to improve cellular acceptance of biomaterials like titanium consists in their surface functionalization using allylamine plasma polymerization under nonthermal conditions. In this surface activation method, an ultrathin and relatively stable plasma polymerized allylamine (PPAAm) layer is deposited onto the material surface changing its hydrophobic nature and providing a hydrophilic coverage for adhering cells [28]. Due to incorporated positively charged amino groups, the PPAAm layer enhances the interaction with negatively charged pericellular matrix components, for example, hyaluronan [29]. Recently, basic cell experiments impressively demonstrated that the PPAAmactivated surfaces promoted adhesion of osteoblasts not only on titanium [28] and calcium phosphate ceramics [30] but also on polymer films and fiber meshes [31]. PPAAm induced early steps in the development of intracellular adhesion components, for example, the actin cytoskeleton and paxillin [29], without disturbing the metabolic activity in living cells [32].

Due to capability of electrospinning to create not only plane geometries but also round shaped and tubular ones and due to the flexible and soft nature of electrospun devices, this technique is considered to have a promising potential in soft tissue and vascular engineering. In this study, we aimed to study efficient PPAAm-coating of poly(L-lactide-co-D/Llactide) (PLA) fiber meshes with hydrophilic characteristics varying the plasma pretreatment of the PLA meshes. We furthermore investigated the initial cell adhesion of epithelial cells on PPAAm-coated PLA meshes and studied the influence of $\gamma$-sterilization as a validated sterilization process used for implant materials. Finally, we present first in vivo data on the tissue acceptance of these scaffolds.

\section{Materials and Methods}

2.1. Materials. A poly(L-lactide-co-D/L-lactide) 70/30 (PLA, Resomer LR 708, Boehringer Ingelheim, Germany) with $M_{w}$ (weight-average molecular weight) $=1.5 \times 10^{6} \mathrm{~g} \mathrm{~mol}^{-1}$ (gel permeation chromatography in chloroform with polystyrene as external standard) was used for electrospinning. Allylamine (for synthesis; $M=57.09 \mathrm{~g} \mathrm{~mol}^{-1}, 99 \%$, VWR, Darmstadt, Germany) was used as precursor for the plasma polymerization process. All other chemicals were of reagent grade.

2.2. Electrospinning. A custom designed electrospinning apparatus consisting of a high-voltage power supply (ESV100, Ingenieurbüro Gerhard Fuhrmann, Leverkusen, Germany), an infusion pump, and a $5 \mathrm{~mL}$ plastic syringe connected by a $25 \mathrm{~cm}$ PTFE tube to a stainless-steel straight-end hollow needle $(0.4 \mathrm{~mm})$ was used. A mirror $(20 \times 20 \mathrm{~cm})$ was used as a collector plate for collecting the electrospun fibers. The needle and the mirror were connected to the ESV-100. The syringe was mounted vertically against the collector, and
TABLE 1: Fiber mesh plasma preactivation process parameters.

\begin{tabular}{lccc}
\hline \multirow{2}{*}{ Method } & \multicolumn{3}{c}{ Preactivation conditions } \\
& Gas composition & Flow $[\mathrm{sccm}]$ & Plasma impact \\
\hline 0 & $\mathrm{O}_{2}$ & 100 & Without preactivation \\
\hline 1 & $\mathrm{O}_{2} / \mathrm{Ar}$ & $100 / 25$ & Pulsed \\
2 & $\mathrm{O}_{2} / \mathrm{Ar}$ & $50 / 75$ & Pulsed \\
3 & $\mathrm{O}_{2} / \mathrm{Ar}$ & $25 / 100$ & Pulsed \\
4 & $\mathrm{Ar}$ & 100 & Pulsed \\
5 & $\mathrm{O}_{2} / \mathrm{Ar}$ & $100 / 25$ & Continued $(10 \mathrm{~s})$ \\
6 & &
\end{tabular}

the sample solution was fed at a constant rate through the syringe to the needle tip. The distance between the needle tip and the mirror was maintained at $18 \mathrm{~cm}$. The voltage applied to the needle was adjusted to $22 \mathrm{kV}$. A solution (3 $\mathrm{wt} \%$ ) of the polymer in chloroform/methanol $(3: 1 \mathrm{v} / \mathrm{v})$ was employed. The flow rate of the solution was controlled at $1.5 \mathrm{~mL} \mathrm{~h}^{-1}$, resulting in the formation of fibers with an average diameter of about $1.67 \mu \mathrm{m}$.

2.3. Fiber Mesh Preactivation. In general, a microwave plasma reactor $(500 \mathrm{~W}, 50 \mathrm{~Pa})$ was used for surface activation of fiber meshes generating pulsed plasma $(10 \mathrm{~ms}$ on $/ 90 \mathrm{~ms}$ off; $50 \mathrm{~s}$ gross time $=5 \mathrm{~s}$ ). Different preactivation conditions were used as given in Table 1.

2.4. PPAAm Coating Process. After the preactivation process polymer meshes were treated without breaking the vacuum in a microwave plasma reactor (V55G Plasma Finish, Schwedt, Germany) in a downstream position $(9 \mathrm{~cm}$ from the microwave coupling window) with respect to disc-like planar plasma of about $2 \mathrm{~cm}$ thickness [28]. The samples were coated by using allylamine as monomer in microwave excited $(2.45 \mathrm{GHz}, 500 \mathrm{~W})$, low pressure $(p=50 \mathrm{~Pa})$ gas discharge plasma with an effective overall treatment duration of $480 \mathrm{~s}$. Two different process regimes of preactivation have been preferred, namely, preactivation methods number 5 and number 6 . For comparison, PPAAm coating was performed without preactivation. Thin layers $(<50 \mathrm{~nm})$ of PPAAm were deposited.

2.5. Surface Analytics. The elemental chemical surface composition and chemical binding properties of PPAAm layers on PLA fiber meshes were determined by X-ray photoelectron spectroscopy (XPS) using an AXIS ULTRA spectrometer (Kratos, Manchester, UK). The measurement conditions were described in detail previously [28]. Briefly, the monochromatic $\mathrm{Al} \mathrm{K} \alpha$ line at $1486 \mathrm{eV}$ ( $150 \mathrm{~W})$, implemented charge neutralization, and pass energy of $80 \mathrm{eV}$ were used for estimating the chemical elemental composition and an energy of $10 \mathrm{eV}$ was used for estimating of the highly resolved Cls peaks. Each surface composition value represents an average over three XPS measuring steps on the surface. Primary amino groups were reacted with 4-trifluoromethylbenzaldehyde (TFBA) at $40^{\circ} \mathrm{C}$ for $2 \mathrm{~h}$ in a saturated gas phase to label them for detection [28]. The polar and disperse part of 
surface free energy was calculated from measurements of contact angles with different liquids. Water, ethylene glycol, and methylene iodide contact angles were determined with the help of the contact angle measuring system OCA 30 (DataPhysics Instruments $\mathrm{GmbH}$, Germany) by the sessile drop method (using software SCA20). Measurements were always performed within $30 \mathrm{~min}$ after sample preparation. The morphology of the meshes has been studied after gold sputtering (coater SCD 004, BAL-TEC, Balzers, Lichtenstein) using the scanning electron microscope DSM 960A (Carl Zeiss, Oberkochen, Germany).

2.6. Cell Cultivation. Human gingiva epithelial cells (Ca9-22, HSRRB, TKG 0485, NIBIO, Osaka, Japan), human uroepithelial cells (SV40-HUC-1, ATCC, CRL-9520, LGC Promochem, Wesel, Germany), and human MG-63 osteoblastic cells (cell line, ATCC, No. CRL-1427, LGC Promochem) were seeded onto untreated and PPAAm-coated (preactivated with method 6, continuous $\mathrm{O}_{2} /$ Ar plasma) fiber meshes with a density of $1 \times 10^{5}$ cells $\mathrm{cm}^{-2}$ and cultured in Dulbecco's modified Eagle medium (DMEM, Invitrogen, Carlsbad, USA) with $10 \%$ fetal calf serum (FCS Gold, PAA Laboratories, Pasching, Austria) or serum free for MG-63 cells [28] and $1 \%$ gentamicin (Ratiopharm, Ulm, Germany) at $37^{\circ} \mathrm{C}$ in a humidified atmosphere with $5 \% \mathrm{CO}_{2}$ for 0.5 and $24 \mathrm{~h}$ to analyze morphology and spreading.

2.7. Cell Spreading. Epithelial cells were trypsinized $(0.05 \%$ trypsin, $0.02 \%$ EDTA, Sigma) at $37^{\circ} \mathrm{C}$ for $3 \mathrm{~min}$, washed in PBS, and stained with the red fluorescent linker PKH26 (PKH26 General Cell Linker Kit, Sigma-Aldrich, St. Louis, MO, USA) for $5 \mathrm{~min}$ in suspension. The vital, membrane stained cells were then seeded onto the fiber meshes and cultured for 0.5 and $24 \mathrm{~h}$. After fixation with $4 \%$ paraformaldehyde (Merck, Darmstadt, Germany), the cells were embedded with a cover slip. The microscopical examinations were performed on the inverted confocal laser scanning microscope LSM 410 (Carl Zeiss, Jena, Germany) equipped with a HeNe laser (excitation $543 \mathrm{~nm}$ ) and the $63 x$ water objective (1.25/0.17, Carl Zeiss). The size of the images was $512 \times 512$ pixels. Spreading (cell area in $\mu \mathrm{m}^{2}$ ) of 40 cells/specimen was measured using the software "area measurement" of the confocal microscope LSM 410.

2.8. Cell Morphology. The cell morphology on the fiber meshes was investigated using a scanning electron microscope DSM 960A (Carl Zeiss, Oberkochen, Germany). For cell analyses, cells were grown for 0.5 and $24 \mathrm{~h}$, fixed with $4 \%$ glutaraldehyde $(24 \mathrm{~h})$, and dehydrated in a vacuum dryer $\left(10 \times 10^{-3}\right.$ mbar, Plano, Wetzlar, Germany). Gold sputtering was performed with the coater (SCD 004, BAL-TEC, Balzers, Lichtenstein). Due to the bulging of the meshes during this drying process, the pictures were taken from different angles (up to $40^{\circ}$ ). This allowed us to visualize the interlocking of the cells and the substrate.

2.9. Sterilization Procedure. Untreated and PPAAm-coated meshes were $\gamma$-sterilized with Cobalt-60 (minimal irradiation dose 25 kGy, Synergy Health Radeberg, Germany).
2.10. In Vivo Study. The local inflammatory tissue response was examined following simultaneous implantation of pieces (size $5 \times 5 \mathrm{~mm}$ ) of untreated and PPAAm-coated electrospun PLA meshes into the neck musculature of 24 male Lewis rats (age, 100 days; mean weight, $395 \pm 13 \mathrm{~g}$ ). After 7, 14, and 56 days, tissue samples containing the PLA meshes were collected from 8 randomly selected animals, and cryosections $(5 \mu \mathrm{m})$ were prepared with a Cryotome 2800 Frigocut $\mathrm{N}$ (Reichert-Jung, Nußloch, Germany). CD68-positive total monocytes and macrophages as well as CD163-positive tissue macrophages were immunohistochemically labelled using the monoclonal antibodies ED1 and ED2, respectively (MorphoSys AbD Serotec, Duesseldorf, Germany). The alkaline phosphatase/anti-alkaline phosphatase detection system (APAAP; DakoCytomation, Hamburg, Germany) with the colorimetric phosphatase substrate New Fuchsin was used to visualize bound primary ED1 and ED2 antibodies. Morphometric evaluation was performed with ImageJ software (U.S. National Institutes of Health, Bethesda, Maryland, USA) by quantification as percentage of positively stained area.

\section{Results and Discussion}

Fiber meshes of biodegradable PLA were fabricated by electrospinning from chloroform/methanol solvent mixtures, and after preactivation of the fiber surface, they were covered with ultrathin PPAAm coating as schematically shown in Figure 1.

As an important task, the conditions of plasma treatment have to be carefully adjusted paying particular attention to the fragility of nanofiber meshes and their thermal sensitivity.

3.1. PLA Fiber Mesh Preactivation. Prior to PPAAm coating, the prepared PLA fiber meshes were preactivated by plasma treatment varying the gas composition and the gas flow in the plasma reactor to establish optimum conditions for the subsequent PPAAm coating.

The values of the contact angles of electrospun meshes measured after different preactivation conditions are compared in Figure 2. As expected, the untreated PLA meshes possess a hydrophobic surface. Whereas in pure argon plasma the contact angle is only slightly changed, pure oxygen plasma drops down the contact angle to $0^{\circ}$ indicating strong hydrophilization of the surface. Mixed $\mathrm{O}_{2} / \mathrm{Ar}$ plasma atmospheres also lead to considerably more hydrophilic surfaces. It was an important aim to perform very mild plasma activation of the PLA surface to avoid any changes or damage of the fiber meshes.

A suitable analytical method to study the surface composition and uniformity of the PLA fibers is XPS possessing an analytical depth of about $10 \mathrm{~nm}$. Figure 3 shows the elemental content for untreated (PLA) and preactivated fiber meshes found by XPS measurements. It can be seen that shortterm, pulsed plasma treatment (effective treatment $=5 \mathrm{~s}$ ) under variation of the $\mathrm{O}_{2} / \mathrm{Ar}$ flow and continuous plasma treatment (method number 6) result only in a slight change of the $\mathrm{C} / \mathrm{O}$ elemental composition. Thus, the influence of 


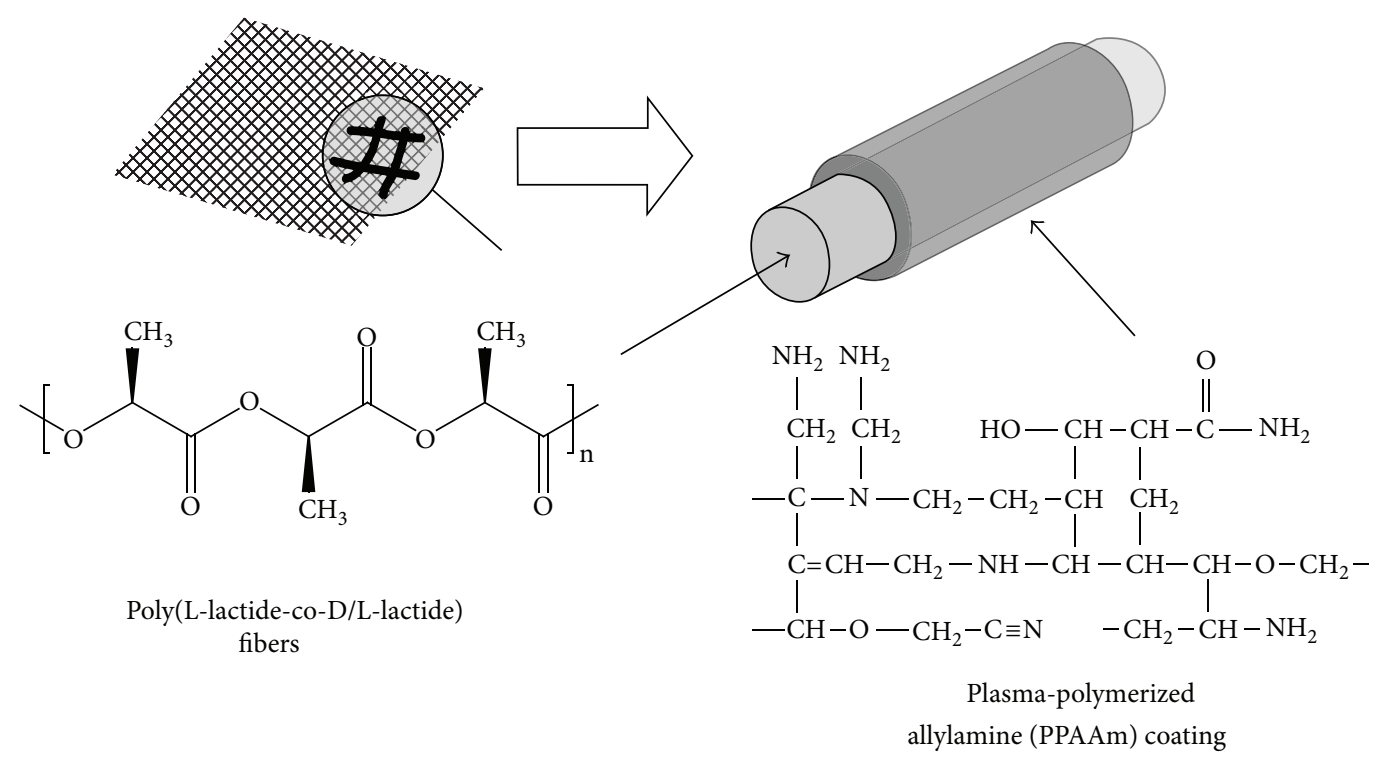

Figure 1: Schematic illustration of surface-coated fiber meshes.

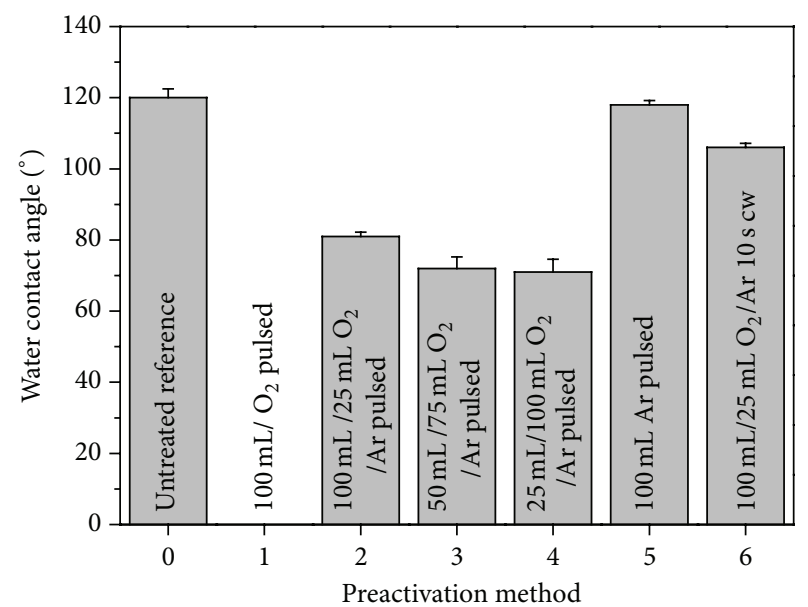

FIGURE 2: Water contact angles of fiber meshes measured after different preactivation conditions (for the numbering of preactivation methods, refer to Table 1).

the preactivation method on the surface composition is only marginal.

3.2. PPAAm Coating. Based on the results of fiber mesh preactivation, PPAAm coating with allylamine as monomer was performed in a microwave reactor without preactivation and after preactivation methods number 5 and number 6 , respectively. Reaction conditions of the plasma polymerization were chosen in such a way that both homogeneous PPAAm coating on the PLA surface with a thickness of about $30 \mathrm{~nm}$ [28] was obtained and no surface alterations of the temperature sensitive fiber mesh could be observed.

As already shown on titanium [28] and schematically depicted in Figure 1 for PLA fibers, the deposited PPAAm

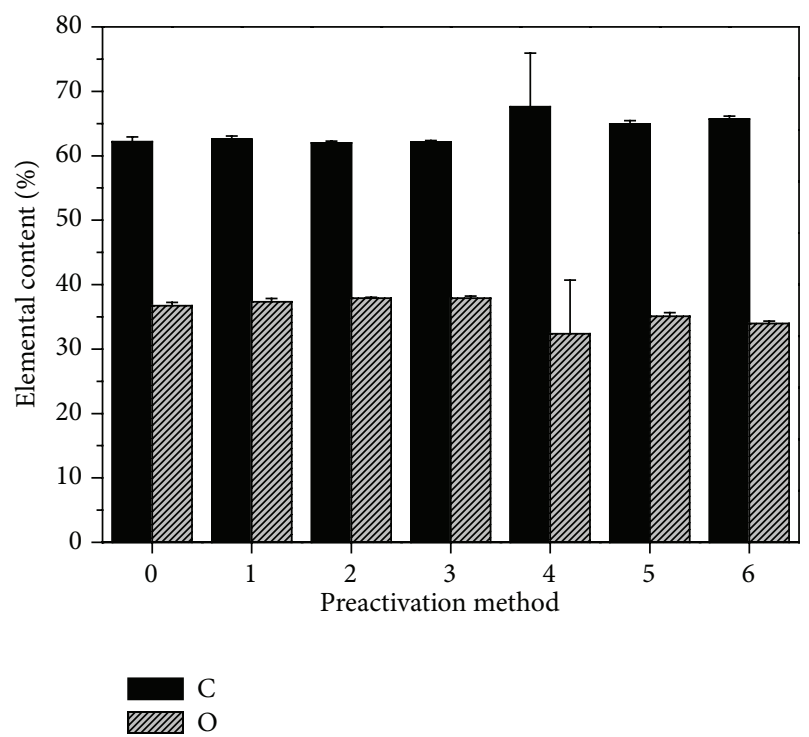

FIGURE 3: XPS investigations of untreated and plasma preactivated PLA fiber meshes.

coating formed a highly cross-linked polymer network containing nitrogen and oxygen functional groups, particularly primary, secondary, and tertiary amino groups.

Figure 4 (left row) shows SEM images of the fabricated porous electrospun fiber matrix with a thickness of $40 \mu \mathrm{m}$ and a mean fiber diameter of $1.67 \mu \mathrm{m}$. The corresponding PPAAm surface-coated fiber meshes are exhibited in the right column of Figure 4 illustrating that the microscopic fiber structure generated by electrospinning was not changed or even damaged by plasma polymerization.

In Figures 5(a) and 5(b), the water contact angles and the surface energies of the PPAAm-coated fiber mesh surfaces obtained after preactivation methods number 5 and number 


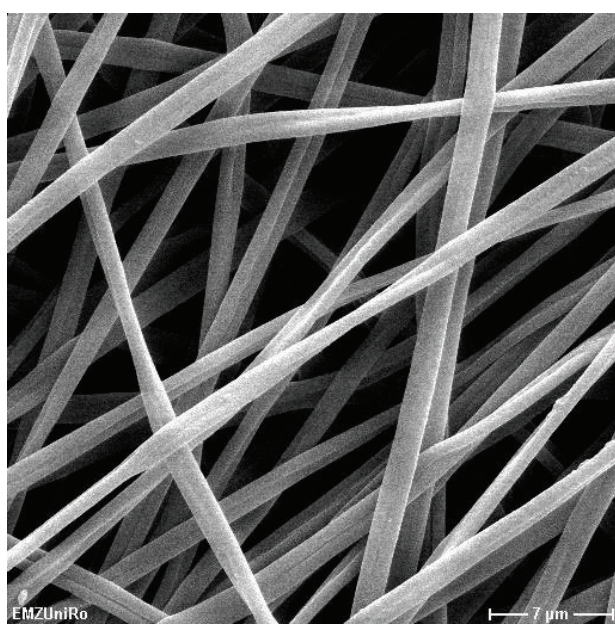

(a)

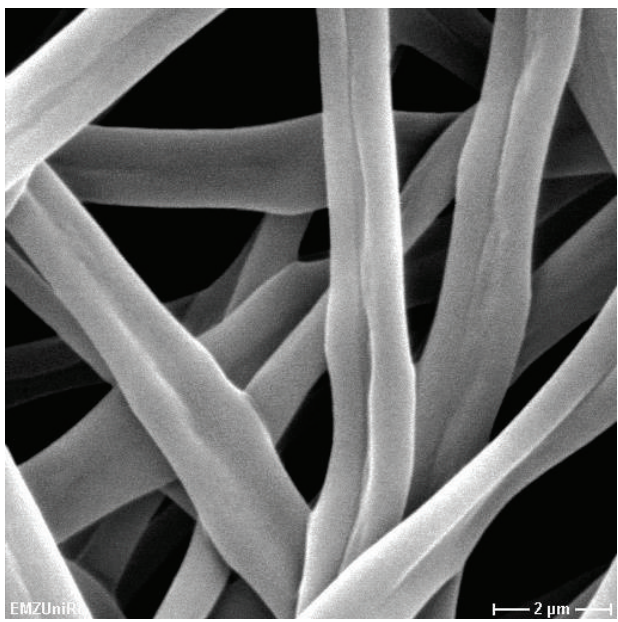

(c)

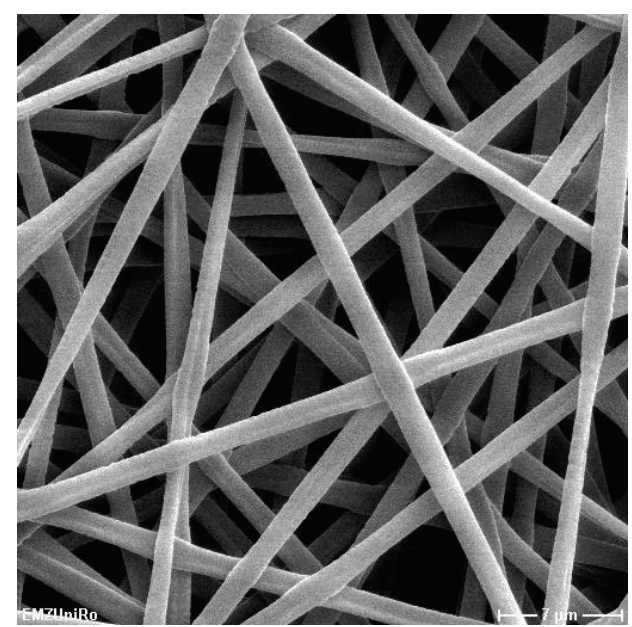

(b)

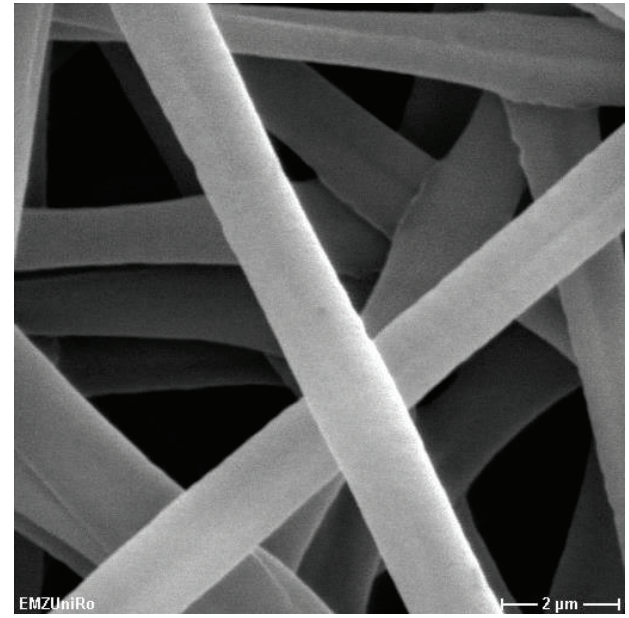

(d)

FIGURE 4: SEM images of untreated (left) and PPAAm-coated (right) electrospun PLA meshes (different magnification, upper row: $\times 3000$, bar $=7 \mu \mathrm{m}$; lower row: $\times 10000$, bar $=2 \mu \mathrm{m})$.

6 and without preactivation, respectively, are shown. In comparison to the PPAAm-coated PLA surface without preactivation possessing a hydrophobic surface (contact angle $>$ $100^{\circ}$ ), the PPAAm-coated fiber meshes, fabricated with mild preactivation, show the desired hydrophilic surfaces with contact angles $<50^{\circ}$ (Figure 5(a)). A somewhat lower water contact angle was found for the PPAAm-treated mesh preactivated by a continuous plasma treatment (method number 6).

The total surface energies measured for the three PPAAm-coated fiber meshes ranged between 58 and $78 \mathrm{mN} / \mathrm{m}$ (Figure 5(b)) illustrating an increase of the polar component of the surface energy from the fiber mesh without preactivation (method number 0 ) to the mesh preactivated by the pulsed plasma treatment (method number 5) and continued to the mesh preactivated by method number 6 (continuous plasma treatment). It could be shown that in comparison to an untreated surface mild preactivation of the PLA surface is necessary to provide a sufficient number of positively charged polar groups on the PPAAm-coated fibers to ensure cell adhesion and proliferation.

Again, XPS was used to examine the surface composition and uniformity of the PLA fibers before and after PPAAm coating. Results are shown in Figure 6. After PPAAm coating, the PLA surface was completely covered by PPAAm characterized by the incorporation of nitrogen in all samples. It can be seen that the preactivation of the PLA fiber meshes by methods 5 and 6 , respectively, leads to a decrease of the oxygen content and simultaneously to an increase of the nitrogen content (N/O ratio of $1.8 \%$ for samples without preactivation versus $\mathrm{N} / \mathrm{O}$ ratio of $4-5 \%$ for preactivated samples) by the deposition of a closed and thicker PPAAm film. After TFBA derivatization of the fiber meshes, which exclusively occurs at the primary amino groups of the coated fiber surface, a higher fluorine content was found for the preactivated PPAAmcoated PLA meshes. The amino group density $\mathrm{NH}_{2} / \mathrm{C}$ could be determined between $2 \%$ for the nonpretreated and $2.5 \%$ for the pretreated fiber meshes. Preactivation of the fiber 


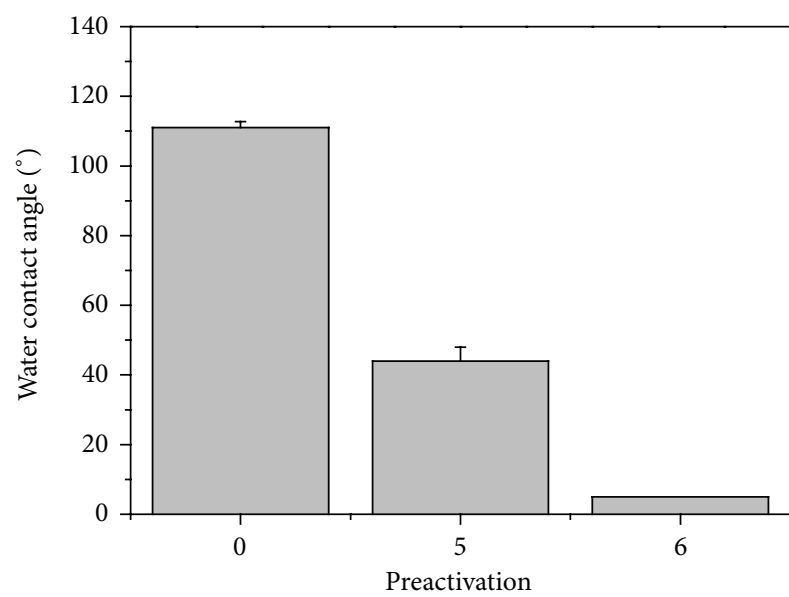

(a)

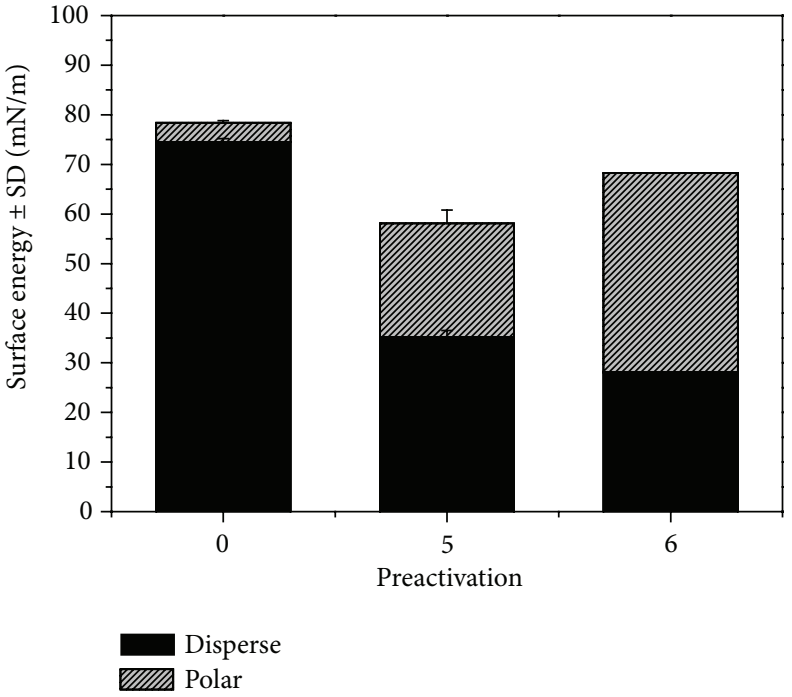

(b)

Figure 5: Water contact angles (a) and surface energies (b) of PPAAm-coated fiber meshes after fiber preactivation by methods number 5 and number 6, respectively, compared to the PPAAm-coated fiber meshes without preactivation (number 0$)(n=5)$.

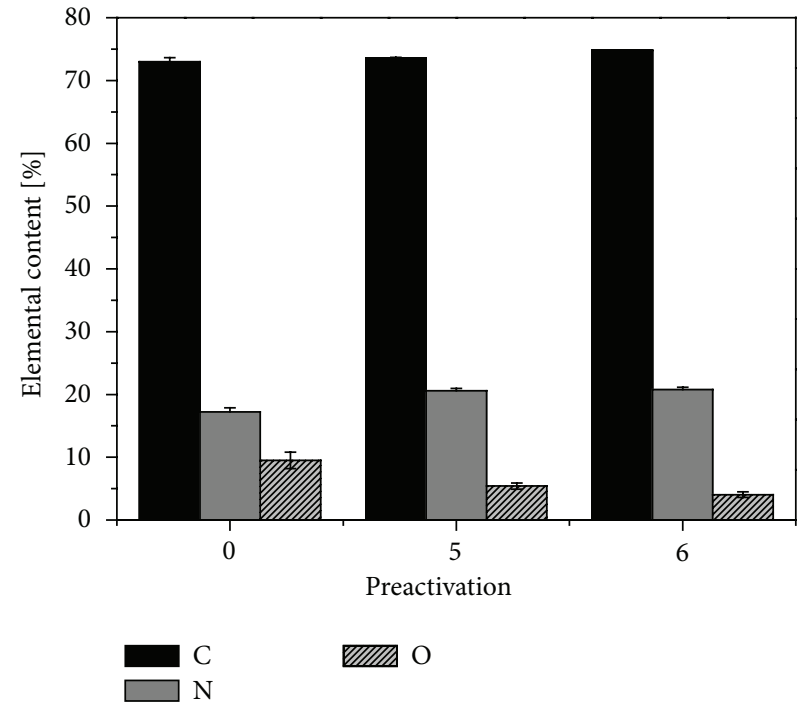

(a)

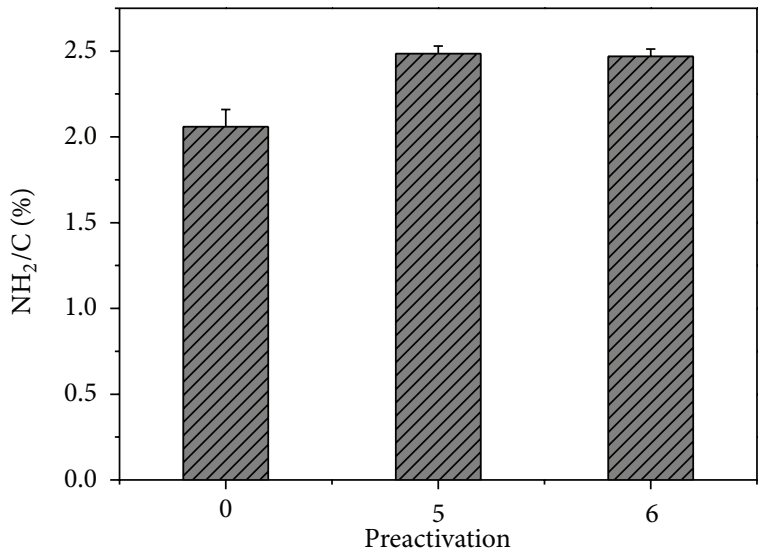

(b)

FIgURE 6: XPS investigations ((a) elemental composition and (b) $\mathrm{NH}_{2} / \mathrm{C}$ ratio) of PPAAm-coated PLA fiber meshes without plasma preactivation and with plasma preactivation (methods 5 and 6), respectively.

meshes is especially necessary for a better thin film deposition by the plasma polymerization process. For all in vitro and in vivo experiments, we utilized the PPAAm functionalized PLA fiber mesh after preactivation with method number 6 (continuous $\mathrm{O}_{2} /$ Ar plasma) due to the water contact angle (see Figure 5).

3.3. Investigations on Cell Spreading. Both human gingiva epithelial cells (Ca9-22) and human uroepithelial cells (SV40HUC-1) showed firm adhesion on PLA and PPAAm-coated fiber meshes. Time-dependent spreading is illustrated in
Table 2 comparing the corresponding cell areas (in $\mu \mathrm{m}^{2}$ ) after 0.5 and $24 \mathrm{~h}$ of cell seeding. As previously described for the MG-63 osteoblastic cells [31], both epithelial cell lines formed larger cell areas on PPAAm-coated PLA mesh surfaces compared to untreated PLA. For the SV40-HUC-1 cells (Figure 7), this effect was more pronounced up to $24 \mathrm{~h}$, whereas in the case of Ca9-22 (Figure 8) the increase in cell areas was only visible after $0.5 \mathrm{~h}$ but in the same range for $24 \mathrm{~h}$.

The morphology of the cells during the adhesion process has also been studied by SEM. In Figure 7, it can be impressively seen how spreading of SV40-HUC-1 uroepithelial 
$30 \mathrm{~min}$
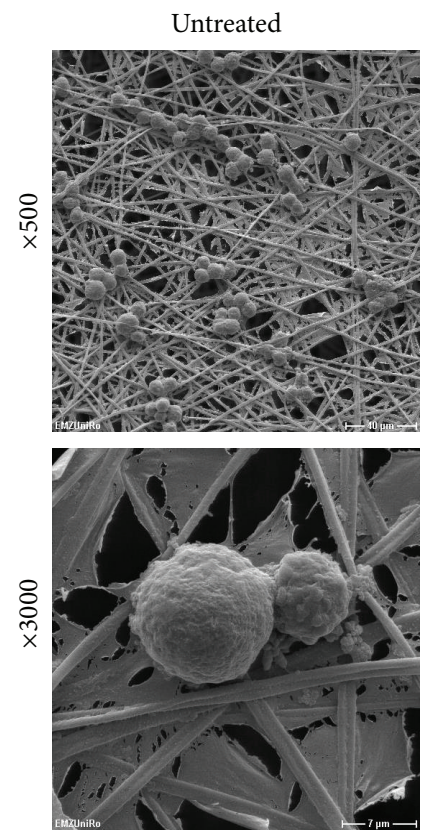
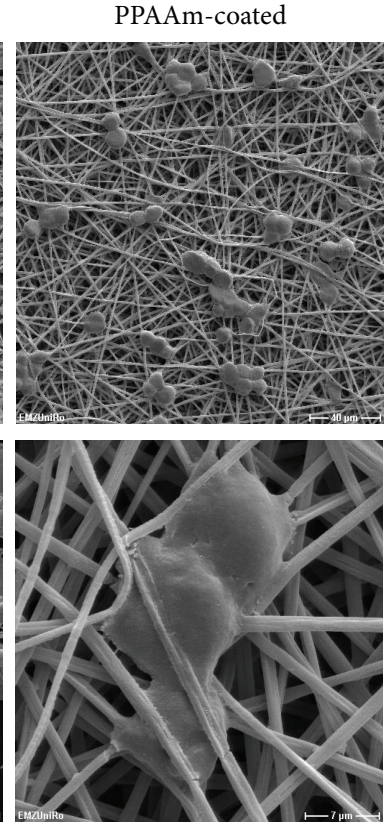

$24 \mathrm{~h}$
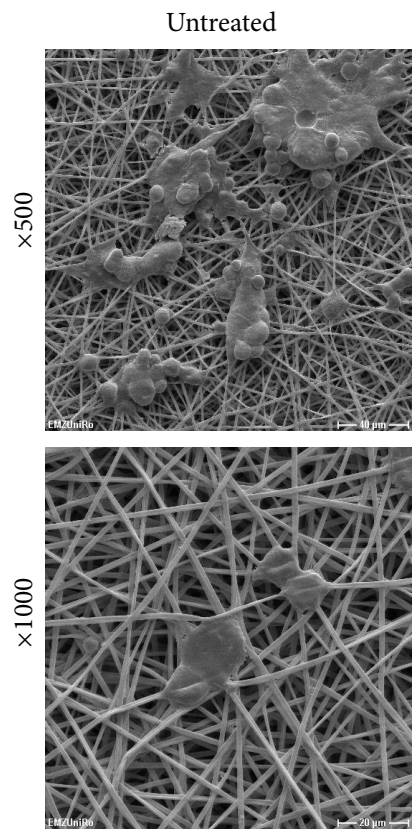
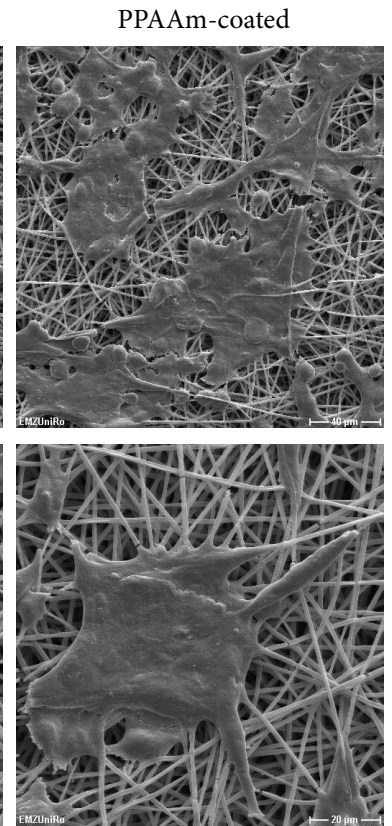

FIGURE 7: SEM images showing spreading of SV40-HUC-1 uroepithelial cells on untreated and PPAAm-coated PLA fiber meshes after 0.5 and $24 \mathrm{~h}$ (bar $=40 \mu \mathrm{m}$ (upper row), $20 \mu \mathrm{m}$ (lower row, right images), and $7 \mu \mathrm{m}$ (lower row, left images)).

$30 \mathrm{~min}$
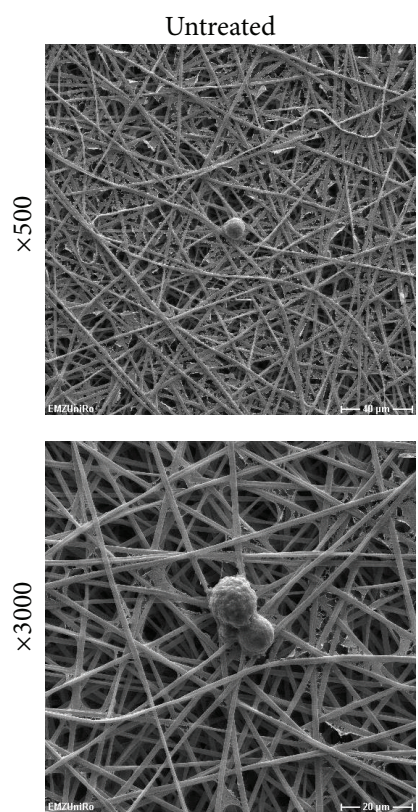
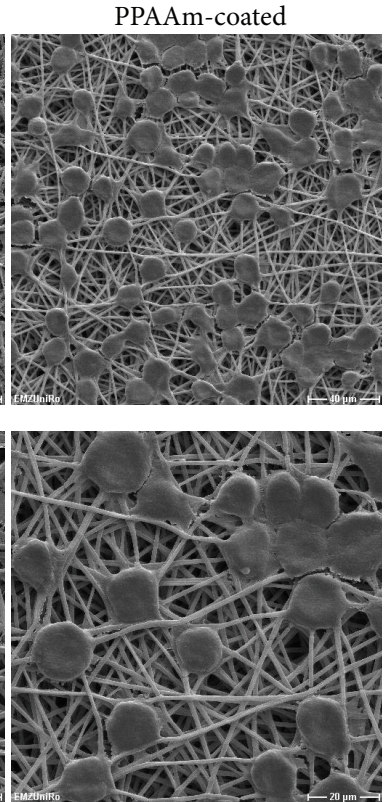

$24 \mathrm{~h}$
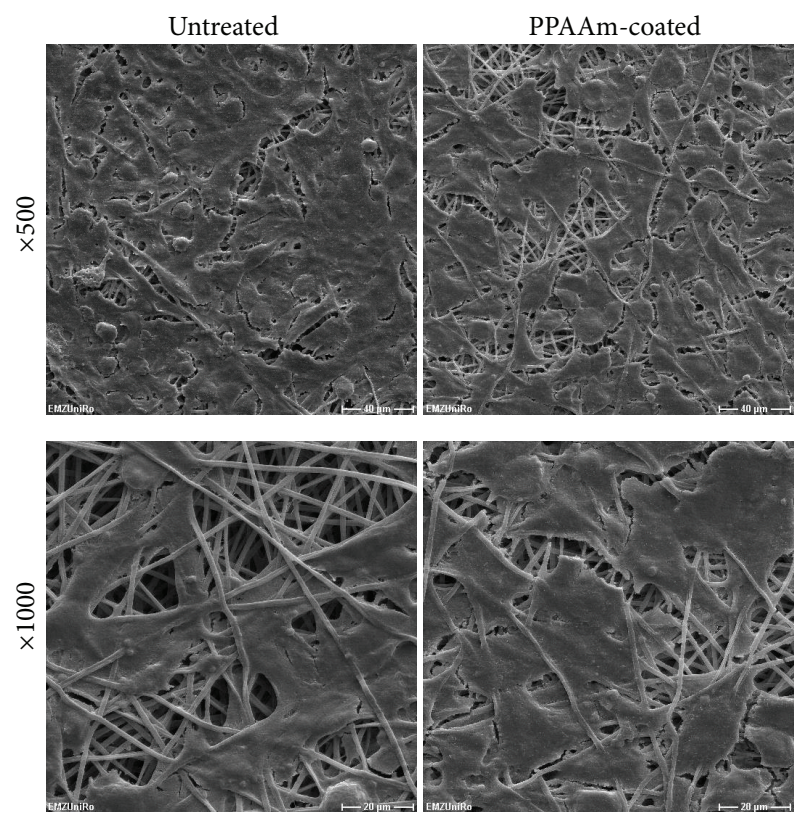

FIGURE 8: SEM images showing spreading of Ca9-22 human gingiva epithelial cells on untreated and PPAAm-coated PLA fiber meshes after 0.5 and $24 \mathrm{~h}$ (bar $=40 \mu \mathrm{m}$ (upper row) and $20 \mu \mathrm{m}$ (lower row)).

cells on PLA fiber mesh structure is supported by plasma treatment with PPAAm, particularly in the initial phase of cell adhesion. The same behaviour is found for Ca9-22 human gingiva epithelial cells in the first phase of occupation (Figure 8).
Overall, these preliminary cell spreading experiments confirm the adhesive capacity of PPAAm coating not only for titanium and calcium phosphate materials as previously observed $[28,30]$ but also for polymers in form of microfibers. Epithelial cells profit by the positively charged 


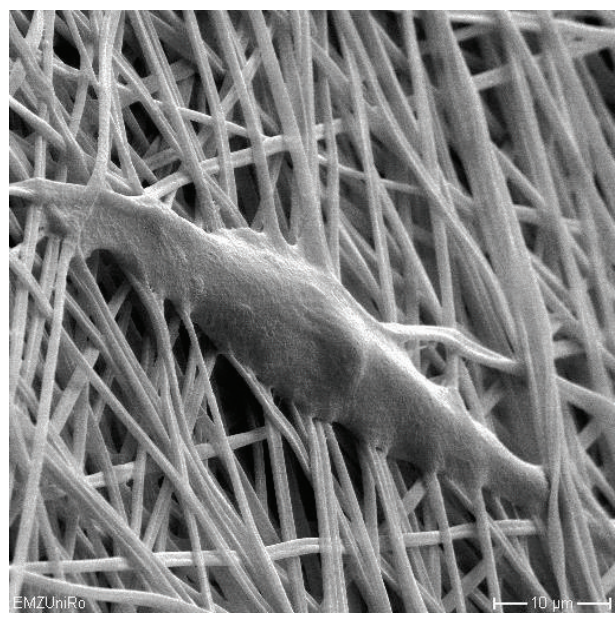

Control

(a)

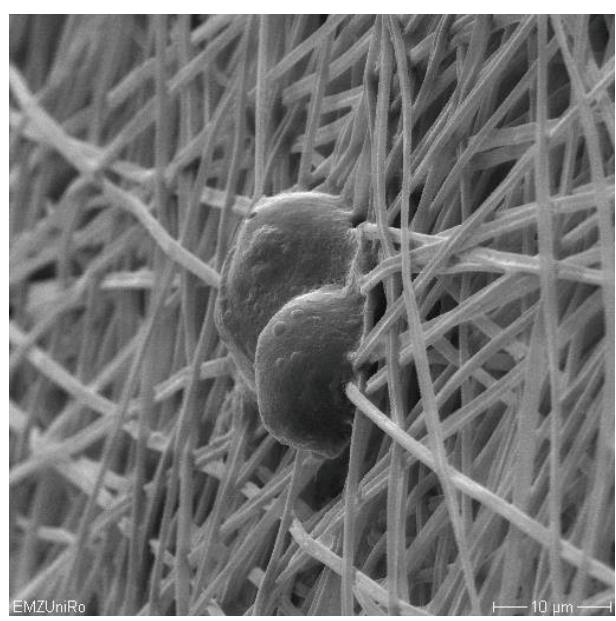

Control $+\gamma$

(c)

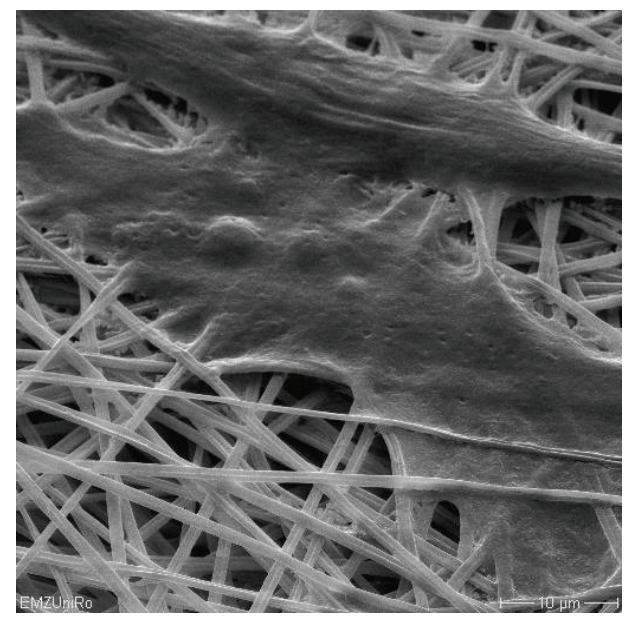

PPAAm

(b)

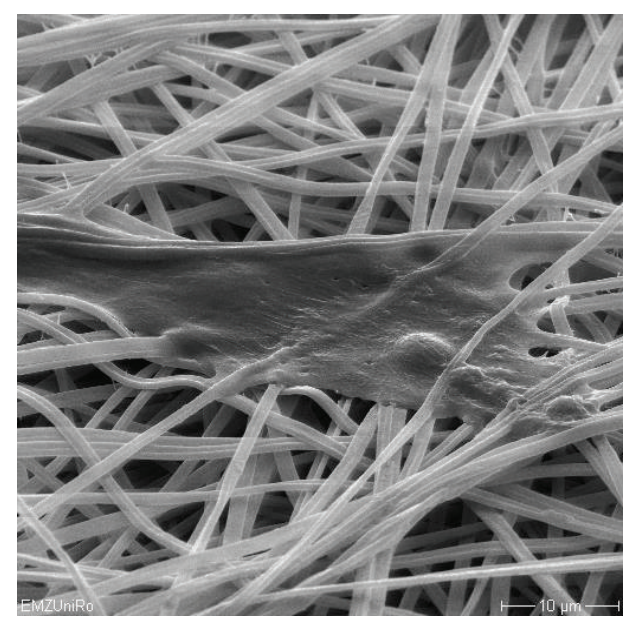

PPAAm $+\gamma$

(d)

FiguRE 9: SEM images of test cells (MG-63) growing for $24 \mathrm{~h}$ on untreated and PPAAm-coated PLA meshes before (upper row) and after $\gamma$-sterilization (lower row). Note that the process of sterilization did not disturb the spreading promoting effect of PPAAm inside the mesh (right, below).

TABLE 2: Cell spreading of SV40-HUC-1 uroepithelial cells and Ca922 gingiva cells on untreated and PPAAm-coated PLA meshes after 0.5 and $24 \mathrm{~h}\left(n=40 ;{ }^{* *} P<0.01 ;{ }^{* * *} P<0.001\right.$; unpaired $t$-test $)$.

\begin{tabular}{lccc}
\hline Cell spreading $\left(\mu \mathrm{m}^{2}\right)$ & & Untreated & PPAAm-coated \\
\hline \multirow{2}{*}{ SV40-HUC-1 } & $\mathbf{3 0 ~} \mathbf{~ m i n}$ & $109.0 \pm 30.4$ & $137.8 \pm 25.6^{* * *}$ \\
& $\mathbf{2 4} \mathbf{~ h}$ & $158.4 \pm 31.2$ & $186.1 \pm 37.9^{* *}$ \\
\hline \multirow{2}{*}{ Ca9-22 } & $\mathbf{3 0 ~} \mathbf{~ m i n}$ & $213.5 \pm 46.8$ & $288.3 \pm 66.7^{* * *}$ \\
& $\mathbf{2 4} \mathbf{h}$ & $315.8 \pm 86.4$ & $315.6 \pm 81.8$ \\
\hline
\end{tabular}

${ }^{* *} P<0.01$ versus untreated; ${ }^{* * *} P<0.001$ versus untreated (mean $\pm \mathrm{SD}$; $n=40$; unpaired $t$-test).

surface and were qualified to rapidly accept the intrinsically hydrophobic biomaterial surface.
3.4. Investigation of Cell Spreading on Sterilized Fiber Meshes. For clinical applications of the PLA meshes, it is necessary to establish a possible sterilization process. We identified $\gamma$-sterilization as a feasible sterilization method for these PPAAm-coated PLA meshes. In Figure 9, it is demonstrated that $\gamma$-sterilization has no influence on the characteristics of the PPAAm nanolayer, which can be seen on the MG-63 cell's capability to spread out quickly on the PPAAm coating.

3.5. In Vivo Study. In a first in vivo study, both untreated electrospun PLA meshes and PPAAm-coated meshes (preactivated by method number 6) were implanted intramuscularly into Lewis rats to investigate the local inflammatory response. The results after 7, 14, and 56 days following implantation in the peri-implant tissue and implant-infiltrating 


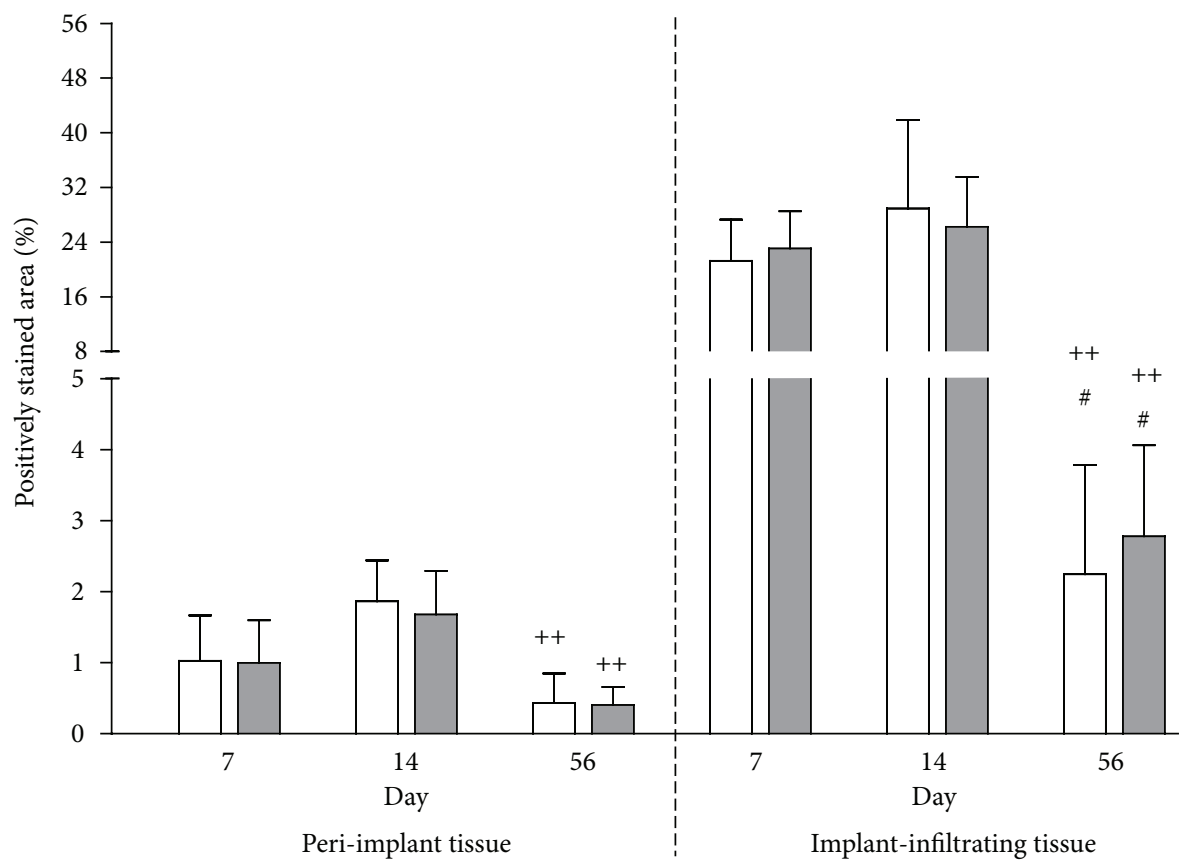

FIGURE 10: Local inflammatory reaction measured as tissue section area positively stained by CD68-positive total monocytes and macrophages in the peri-implant tissue and implant-infiltrating tissue following i.m. implantation of untreated electrospun PLA meshes (white columns) or PPAAm-coated meshes (gray columns) after 7, 14, and 56 days in Lewis rats. Columns represent the mean and error bars represent the standard deviation of 8 rats per experimental day. Hash symbols (\#) indicate a significant difference $(P<0.05)$ versus day 7 , and plus symbols $(+)$ indicate a significant difference $(P<0.01)$ versus day 14 (Wilcoxon rank-sum test).

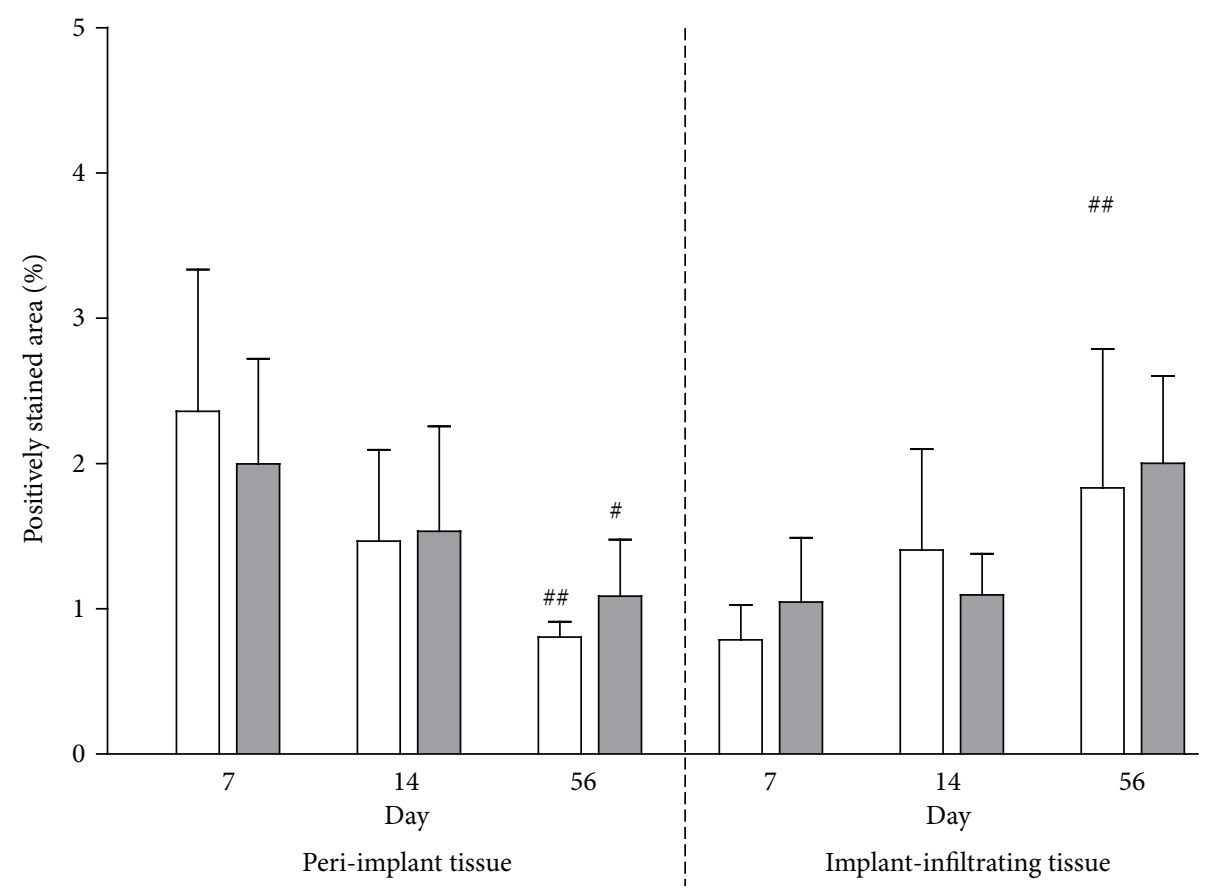

FIGURE 11: Local inflammatory reaction measured as tissue section area positively stained in immunohistochemistry by CD163-positive tissue macrophages in the peri-implant tissue and implant-infiltrating tissue following i.m. implantation of untreated electrospun PLA meshes (white columns) or PPAAm-coated meshes (gray columns) after 7, 14, and 56 days in Lewis rats. Columns represent the mean, and error bars represent the standard deviation of 8 rats per experimental day. Hash symbols (\#) indicate a significant difference $\left({ }^{\#} P<0.05\right.$; $\left.{ }^{\# \#} P<0.01\right)$ versus day 7 (Wilcoxon rank-sum test). 


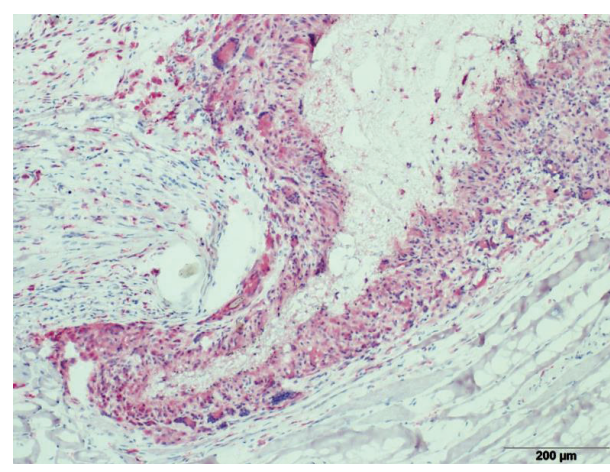

(a)

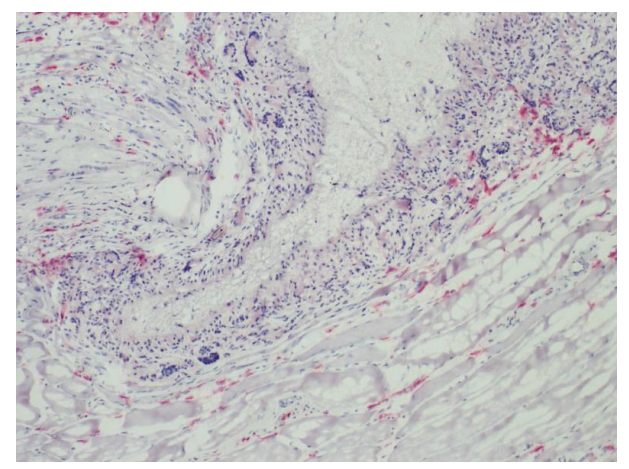

(b)

FIGURE 12: Exemplary immunohistochemical images for staining of CD68-positive total monocytes and macrophages (ED1, left) and CD163positive tissue macrophages (ED2, right) from experimental day 14 for an untreated PLA mesh sample.

tissue are given for the CD68-positive total monocytes and macrophages in Figure 10 and for the CD163-positive tissue macrophages in Figure 11.

The local inflammatory reaction of CD68-positive monocytes and macrophages did not differ between the untreated and the PPAAm-coated meshes on any experimental day and decreased significantly for both mesh types after day 14 , consistent with a change from an acute to a chronic phase of inflammation.

Particularly on days 7 and 14 for both mesh types, the inflammatory response within the implant-infiltrating tissue was 10 - to 20 -fold higher than in the peri-implant tissue $(P=0.0078)$. Similar to the CD68-positive monocytes and macrophages, there was no significant difference between both mesh types on any experimental day for the CD163positive tissue macrophages. In the peri-implant tissue, a significant decrease was observed over time (day 56 versus day 7) for both meshes, accompanied by a significant increase in the implant-infiltrating tissue for the uncoated meshes but not for the PPAAm-coated meshes. These observations are also in accordance with a shift from acute to chronic inflammation. In the peri-implant tissue, the response of CD68positive monocytes and macrophages and CD163-positive tissue macrophages was comparable over the study course, indicating that these macrophages were predominantly tissue macrophages. In contrast, there were about 10-fold more CD68-positive monocytes and macrophages than CD163positive tissue macrophages on days 7 and 14 in the implantinfiltrating tissue, suggesting an early influx of macrophages into this tissue area. Examples of immunohistochemical images for staining of CD68-positive total monocytes and macrophages and CD163-positive tissue macrophages from experimental day 14 for an untreated PLA mesh sample are shown in Figure 12.

Overall, the results from the histological examination demonstrate that the PPAAm-coated meshes were comparable to the untreated meshes regarding the local inflammatory tissue response. Our long-term experiments in rats up to six weeks recently revealed that this PPAAm nanolayer on titanium alloys induced bone growth and improved the boneto-implant contact area decisively [33].

\section{Conclusions}

In this study, a plasma polymerization process using allylamine monomer was adapted to cover the fiber surfaces of electrospun meshes prepared from PLA. Efficient preactivation conditions for the fiber meshes before PPAAm coating have been established, and method number $6\left(\mathrm{O}_{2} / \mathrm{Ar}\right.$ $=100 / 25 \mathrm{~mL}$, continuous wave $10 \mathrm{~s}$ ) was favored for in vitro and in vivo experiments. The PPAAm coating did not affect the fragile microstructure of the fiber mesh preserving the advantageous structural properties of these materials with regard to their use in tissue engineering. The PPAAm coating providing free amino groups on the fiber surface led to a drastic change of the hydrophobic nature of PLA meshes into a hydrophilic polymer network as shown by contact angle measurements. In vitro cell experiments using human gingiva epithelial cells (Ca9-22), human uroepithelial cells (SV40-HUC-1), and MG-63 cells confirmed an improved cell spreading on positively charged, amino group-containing PPAAm surfaces already after $0.5 \mathrm{~h}$ of incubation. In addition, cells melt into these conditioned meshes. The $\gamma$-sterilization process did not hamper these findings. First in vivo data on the biocompatibility of PPAAm-modified polylactide meshes demonstrated that the coating has no influence on the local inflammatory reaction. For both PPAAm-coated and untreated mesh types, the time course of the examined local inflammatory reactions was generally characterized by a change from acute to chronic state as established for implantation-related inflammation. Furthermore, the response was stronger in the implant-infiltrating tissue than in the peri-implant tissue, indicating that these inflammatory processes were localized to the implant site without farreaching effects into distant tissue areas.

Based on these results, the plasma-assisted attachment of positively charged amino groups onto biodegradable synthetic polymer mesh surfaces represents a promising 
approach to improve the cellular acceptance of these materials.

\section{Conflict of Interests}

The authors declare that there is no conflict of interests regarding the publication of this paper.

\section{Acknowledgments}

Birgit Finke, Henrike Rebl, and Uwe Walschus kindly acknowledge the support of the BMBF German Pilot Program Campus PlasmaMed (Subproject PlasmaImp, 13N9775, 13N9779, 13N11188, and 13N11183). M. Schnabelrauch and R. Wyrwa (INNOVENT) thank the German Federal Ministry of Economics for financial support (INNO-KOM-Ost, MF110109). The authors appreciate technical support of $U$. Kellner, G. Friedrichs, U. Lindemann, R. Ihrke (INP Greifswald), K. Tornow (University of Greifswald), J. Wenzel, and J. Wetzel (University Medical Center Rostock) and the Electron Microscopy Center of the University of Rostock.

\section{References}

[1] T. J. Sill and H. A. von Recum, "Electrospinning: applications in drug delivery and tissue engineering," Biomaterials, vol. 29, no. 13, pp. 1989-2006, 2008.

[2] S. Agarwal, J. H. Wendorff, and A. Greiner, "Progress in the field of electrospinning for tissue engineering applications," Advanced Materials, vol. 21, no. 32-33, pp. 3343-3351, 2009.

[3] B. M. Baker, A. M. Handorf, L. C. Ionescu, W.-J. Li, and R. L. Mauck, "New directions in nanofibrous scaffolds for soft tissue engineering and regeneration," Expert Review of Medical Devices, vol. 6, no. 5, pp. 515-532, 2009.

[4] W. Liu, S. Thomopoulos, and Y. Xia, "Electrospun nanofibers for regenerative medicine," Advanced Healthcare Materials, vol. 1, no. 1, pp. 10-25, 2012.

[5] A. J. Meinel, O. Germershaus, T. Luhmann, H. P. Merkle, and L. Meinel, "Electrospun matrices for localized drug delivery: current technologies and selected biomedical applications," European Journal of Pharmaceutics and Biopharmaceutics, vol. 81, no. 1, pp. 1-13, 2012.

[6] Z.-M. Huang, Y.-Z. Zhang, M. Kotaki, and S. Ramakrishna, "A review on polymer nanofibers by electrospinning and their applications in nanocomposites," Composites Science and Technology, vol. 63, no. 15, pp. 2223-2253, 2003.

[7] D. H. Reneker, A. L. Yarin, E. Zussman, and H. Xu, "Electrospinning of nanofibers from polymer solutions and melts," Advances in Applied Mechanics, vol. 41, pp. 43-346, 2007.

[8] W.-E. Teo, W. He, and S. Ramakrishna, "Electrospun scaffold tailored for tissue-specific extracellular matrix," Biotechnology Journal, vol. 1, no. 9, pp. 918-929, 2006.

[9] A. Szentivanyi, T. Chakradeo, H. Zernetsch, and B. Glasmacher, "Electrospun cellular microenvironments: understanding controlled release and scaffold structure," Advanced Drug Delivery Reviews, vol. 63, no. 4, pp. 209-220, 2011.

[10] Z. Ma, M. Kotaki, R. Inai, and S. Ramakrishna, "Potential of nanofiber matrix as tissue-engineering scaffolds," Tissue Engineering, vol. 11, no. 1-2, pp. 101-109, 2005.
[11] S. P. Zhong, Y. Z. Zhang, and C. T. Lim, "Tissue scaffolds for skin wound healing and dermal reconstruction," Wiley Interdisciplinary Reviews: Nanomedicine and Nanobiotechnology, vol. 2, no. 5, pp. 510-525, 2010.

[12] J. A. Matthews, G. E. Wnek, D. G. Simpson, and G. L. Bowlin, "Electrospinning of collagen nanofibers," Biomacromolecules, vol. 3, no. 2, pp. 232-238, 2002.

[13] D. B. Khadka and D. T. Haynie, "Protein- and peptide-based electrospun nanofibers in medical biomaterials," Nanomedicine: Nanotechnology, Biology, and Medicine, vol. 8, no. 8, pp. 12421262, 2012.

[14] X. Zhang, M. R. Reagan, and D. L. Kaplan, "Electrospun silk biomaterial scaffolds for regenerative medicine," Advanced Drug Delivery Reviews, vol. 61, no. 12, pp. 988-1006, 2009.

[15] K. Y. Lee, L. Jeong, Y. O. Kang, S. J. Lee, and W. H. Park, "Electrospinning of polysaccharides for regenerative medicine," Advanced Drug Delivery Reviews, vol. 61, no. 12, pp. 1020-1032, 2009.

[16] E. Piskin, N. Bölgen, S. Egri, and I. A. Isoglu, "Electrospun matrices made of poly $(\alpha$-hydroxy acids) for medical use," Nanomedicine, vol. 2, no. 4, pp. 441-457, 2007.

[17] Q. Su, A. Zhao, H. Peng, and S. Zhou, "Preparation and characterization of biodegradable electrospun polyanhydride nano/microfibers," Journal of Nanoscience and Nanotechnology, vol. 10, no. 10, pp. 6369-6375, 2010.

[18] S. A. Guelcher, "Biodegradable polyurethanes: synthesis and applications in regenerative medicine," Tissue Engineering B: Reviews, vol. 14, no. 1, pp. 3-17, 2008.

[19] X. Zong, H. Bien, C.-Y. Chung et al., "Electrospun fine-textured scaffolds for heart tissue constructs," Biomaterials, vol. 26, no. 26, pp. 5330-5338, 2005.

[20] X. M. Mo, C. Y. Xu, M. Kotaki, and S. Ramakrishna, "Electrospun P(LLA-CL) nanofiber: a biomimetic extracellular matrix for smooth muscle cell and endothelial cell proliferation," Biomaterials, vol. 25, no. 10, pp. 1883-1890, 2004.

[21] M. Gümüşderelioglu, S. Dalkiranoğlu, R. S. T. Aydin, and S. Çakmak, "A novel dermal substitute based on biofunctionalized electrospun PCL nanofibrous matrix," Journal of Biomedical Materials Research A, vol. 98, no. 3, pp. 461-472, 2011.

[22] P. J. Kluger, R. Wyrwa, J. Weisser et al., "Electrospun poly $(\mathrm{d} / \mathrm{l}$ lactide-co-l-lactide) hybrid matrix: a novel scaffold material for soft tissue engineering," Journal of Materials Science: Materials in Medicine, vol. 21, no. 9, pp. 2665-2671, 2010.

[23] A. S. Badami, M. R. Kreke, M. S. Thompson, J. S. Riffle, and A. S. Goldstein, "Effect of fiber diameter on spreading, proliferation, and differentiation of osteoblastic cells on electrospun poly(lactic acid) substrates," Biomaterials, vol. 27, no. 4, pp. 596606, 2006.

[24] S. Wang, W. Cui, and J. Bei, "Bulk and surface modifications of polylactide," Analytical and Bioanalytical Chemistry, vol. 381, no. 3, pp. 547-556, 2005.

[25] D.-J. Yang, L.-F. Zhang, L. Xu, C.-D. Xiong, J. Ding, and Y.-Z. Wang, "Fabrication and characterization of hydrophilic electrospun membranes made from the block copolymer of poly(ethylene glycol-co-lactide)," Journal of Biomedical Materials Research $A$, vol. 82, no. 3, pp. 680-688, 2007.

[26] Z.-Q. Feng, H.-J. Lu, M. K. Leach et al., "The influence of typeI collagen-coated PLLA aligned nanofibers on growth of blood outgrowth endothelial cells," Biomedical Materials, vol. 5, no. 6, Article ID 065011, 2010. 
[27] T. G. Kim and T. G. Park, "Biomimicking extracellular matrix: cell adhesive RGD peptide modified electrospun poly(D,Llactic-co-glycolic acid) nanofiber mesh," Tissue Engineering, vol. 12, no. 2, pp. 221-233, 2006.

[28] B. Finke, F. Luethen, K. Schroeder et al., "The effect of positively charged plasma polymerization on initial osteoblastic focal adhesion on titanium surfaces," Biomaterials, vol. 28, no. 30, pp. 4521-4534, 2007.

[29] J. B. Nebe and F. Lüthen, "Integrin- and hyaluronan-mediated cell adhesion on titanium," in Metallic Biomaterial Interactions, J. Breme, C. J. Kirkpatrick, and R. Thull, Eds., pp. 179-182, Wiley-VCH, Weinheim, Germany, 2008.

[30] J. B. Nebe, M. Cornelsen, A. Quade et al., "Osteoblast behavior in vitro in porous calcium phosphate composite scaffolds, surface activated with a cell adhesive plasma polymer layer," Materials Science Forum, vol. 706-709, pp. 566-571, 2012.

[31] R. Wyrwa, B. Finke, H. Rebl et al., "Design of plasma surfaceactivated, electrospun polylactide non-wovens with improved cell acceptance," Advanced Engineering Materials, vol. 13, no. 5, pp. B165-B171, 2011.

[32] H. Rebl, B. Finke, K. Schroeder, and J. B. Nebe, "Timedependent metabolic activity and adhesion of human osteoblast-like cells on sensor chips with a plasma polymer nanolayer," International Journal of Artificial Organs, vol. 33, no. 10, pp. 738-748, 2010.

[33] C. Gabler, C. Zietz, R. Göhler et al., "Evaluation of osseointegration of titanium alloyed implants modified by plasma polymerization," International Journal of Molecular Sciences, vol. 15, no. 2, pp. 2454-2464, 2014. 

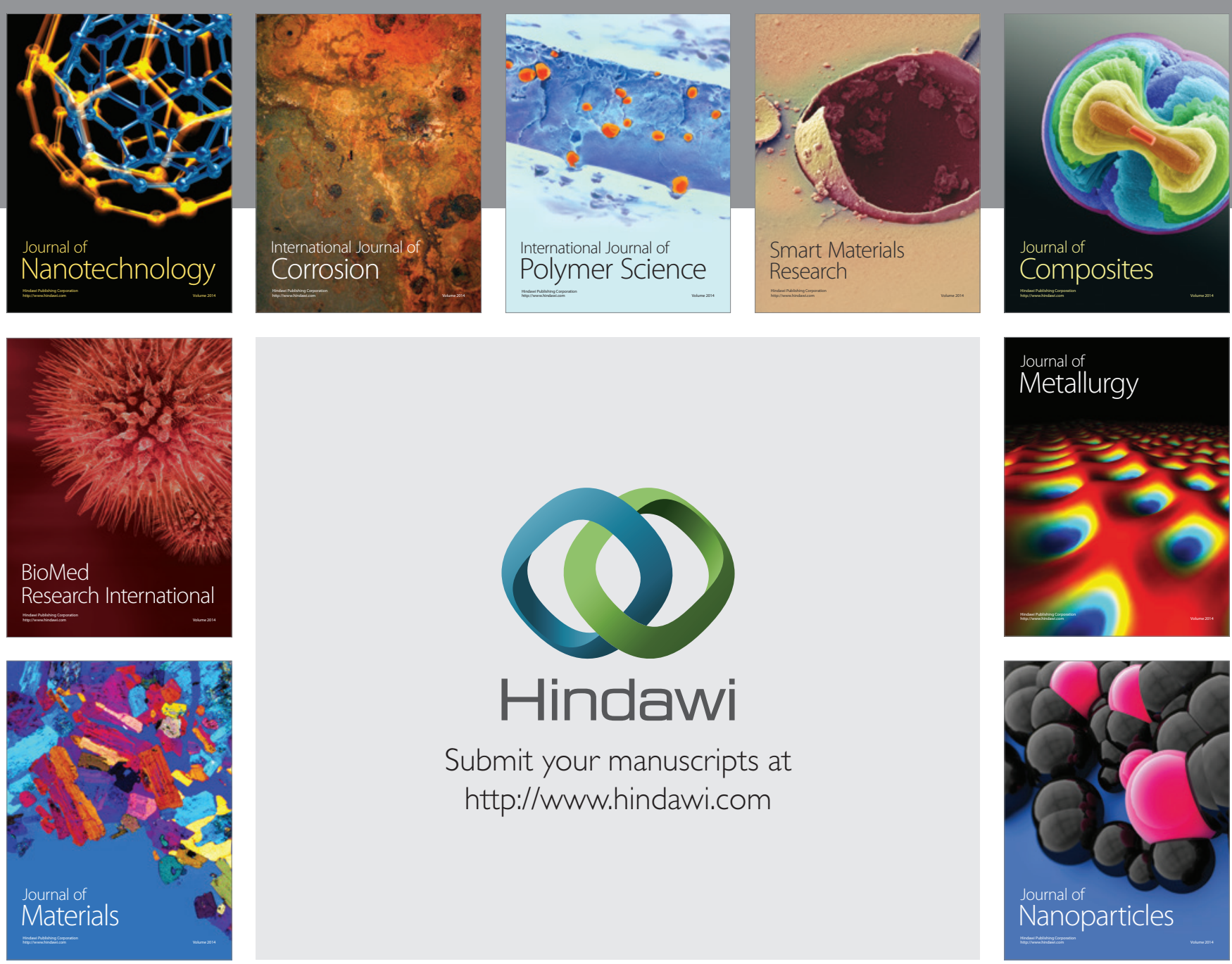

Submit your manuscripts at http://www.hindawi.com
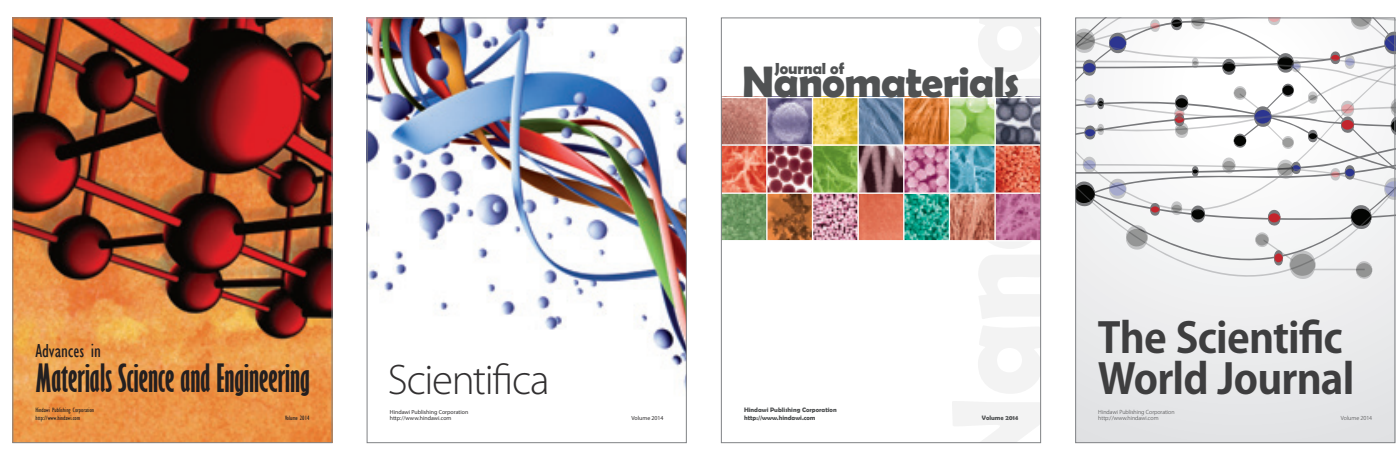

\section{The Scientific World Journal}
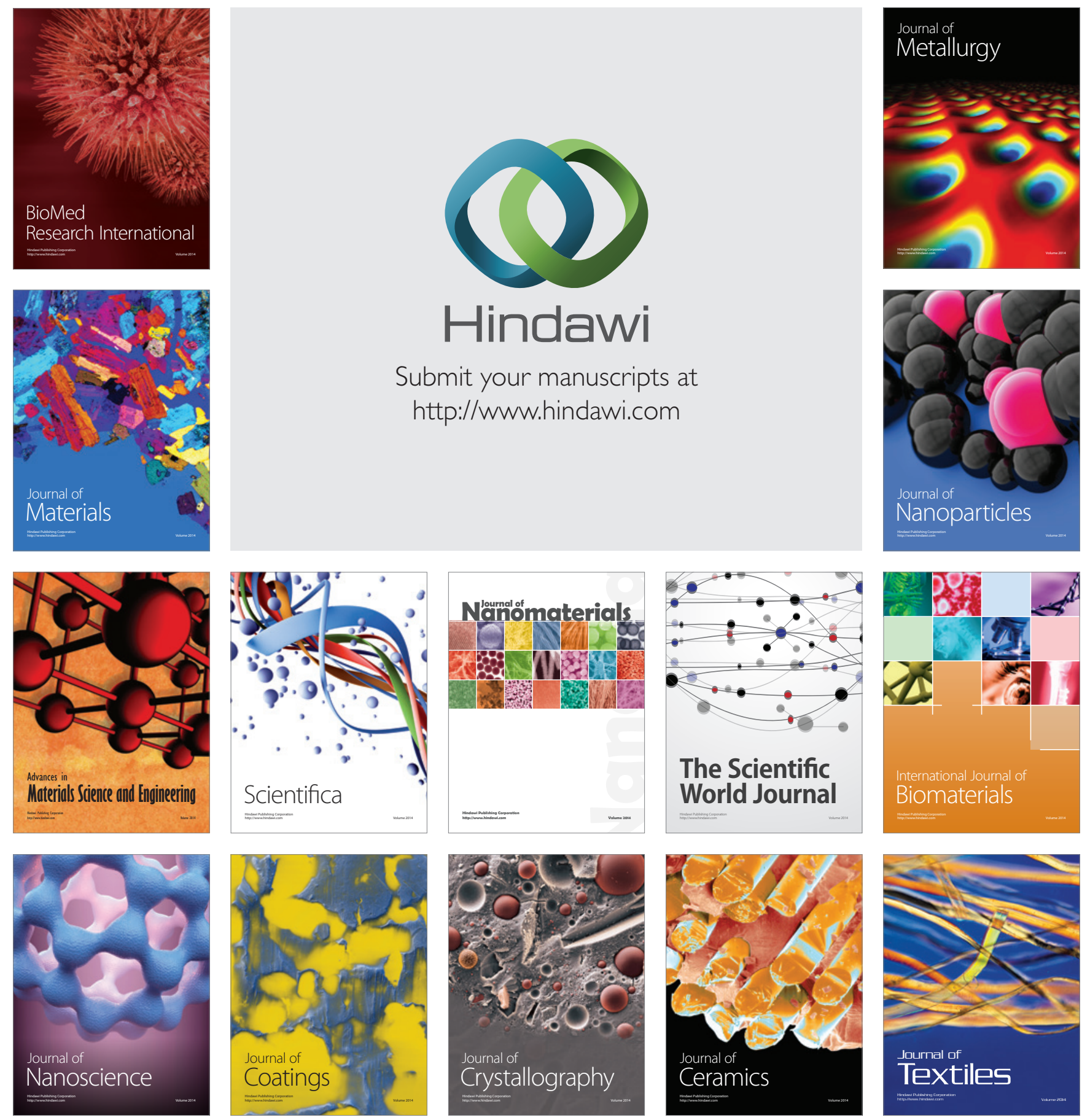